\title{
ESTIMATION OF GENETIC PARAMETERS FOR SKELETAL DEFECTS IN BROILER CHICKENS
}

\author{
J. T. MERCER † AND W. G. HILL \\ Institute of Animal Genetics, University of Edinburgh, West Mains Road, Edinburgh EH9 3JN, \\ U.K.
}

Received 13.xii.83

SUMMARY

\begin{abstract}
Analysis of variance and proband methods for estimating heritabilities and genetic correlations in low incidence, binomially distributed traits are compared using a computer simulation. It is concluded that reliable but conservative results are obtained by the proband method for heritabilities while analysis of variance techniques are more appropriate for estimating genetic correlations. These results apply providing that the incidences involved are not much less than 0.01 , and that the true genetic correlation is not very small.

These methods are then applied to pedigree broiler data, including information on live-weight and various skeletal defects. It appears that all the defects considered are heritable, that leg problems have positive genetic correlations with weight, and that it is reasonable to group abnormalities together for the purposes of selection.
\end{abstract}

\section{INTRODUCTION}

Skeletal defects have been a source of concern to the poultry industry for some years. It has been estimated that leg weaknesses alone account for losses of over $\$ 28 \mathrm{~m}$ per annum in the U.S.A. (Craig, 1978). Despite the fact that many selection programmes now operate against them, little is known about the genetics of such abnormalities. Indeed, no attempt has been made to estimate genetic parameters such as heritability and genetic correlations on large data sets obtained from commercial populations, although these do now exist. Such estimates as are available, as for tibial dyschondroplasia (Sheridan et al., 1978), are the results of relatively small-scale selection experiments.

The paucity of information in this field may be attributable to problems with both collection and analysis of data. Identification of individual defects requires trained personnel, and there is much confusion in the literature as to which problems can be considered sufficiently distinct as to warrant independent status. As abnormalities are relatively scarce, large numbers of birds must be examined before the data on affected animals are sufficient to permit genetic analysis. Inevitably, birds are scored on a $0-1$ basis, according to whether a condition is present or absent. Obviously, methods of estimating genetic parameters of continuously distributed traits do not apply in this instance, as the variances of all-or-none traits are not independent of their means.

This paper compares two basis methods of analysing binomially distributed (0-1) data. Lush et al. (1948) and Robertson and Lerner (1949) proposed an analysis of variance technique for the analysis of such data. Estimates of heritability obtained in this way can be converted onto a

$\uparrow$ Present address: Northern Pig Development Company, Manor House, Beeford, Driffield, North Humberside. 
hypothetical underlying continuous scale using the transformation of Robertson and Lerner (1949), which is $p(1-p) / z^{2}$, where $p$ is the population incidence and $z$ is the height of the ordinate of a standardised normal at the threshold point corresponding to $p$. The proband method (Falconer, $1965,1967)$ assumes that an animal has an underlying liability to a trait, such as a skeletal defect, the expression of which is only visible above a certain threshold point. Heritability estimates are therefore made on a continuous scale and arise from a consideration of the incidence in a population in relation to that of the relatives of affected individuals. Particular emphasis is placed on the applicability of the analysis of variance and proband methods described by these authors to data in which the incidences are very low, as is the case with the abnormalities considered here.

The methods examined were then applied to a large commercial data set, in which information on live-weight was also included. It was therefore possible to examine not only the relationship among defect traits, but also that between defect traits and the main trait under selection.

\section{ESTIMATION OF HERITABILITY AND GENETIC CORRELATION}

The analysis of variance method used is derived from that proposed by Robertson and Lerner (1949), and reviewed by Elston (1977) and Hill and Smith (1977). Analyses were performed by least squares using the LSML76 program (Harvey, 1977). Estimates of heritability calculated on a $0-1$ basis were transformed to a continuous scale in all cases.

In the proband method all individuals having the defect in the population are taken as the probands and the incidence in their relatives, either halfor full-sibs, computed. These are then, following Falconer (1965), transformed into the underlying liabilities of affected individuals and their relatives. The difference between the two, expressed in normal deviates, may be considered to be equivalent to a selection response, and the difference in mean liability between probands and the population as a whole is the selection differential. Thus the regression of relatives on probands is

$$
b=\left(x_{g}-x_{\text {rel }}\right) / a
$$

and the estimate of heritability is

$$
h^{2}=b / \text { (coefficient of relationship of relatives and probands); }
$$

where: $x_{g}=$ the deviation of the abscissa of a standardized normal deviate, corresponding to the population incidence, from the population mean liability; $x_{\text {rel }}=$ the deviation of the abscissa of a standardised normal deviate, corresponding to the population incidence of relatives of affected individuals, from the mean liability of the population of relatives; $a=$ the deviation of the mean liability of affected individuals from the expected liability of the whole population, in standard deviation units.

In a manner analogous to that presented above we can consider the selection response produced in one trait from selection on another in order to obtain a genetic correlation, $r_{G}$ :

$$
\begin{aligned}
b_{j i} & =\text { regression of liability in trait } j \text { of relatives on probands affected by } \\
& \text { trait } i \\
& =\left[x_{g}(\text { trait } j)-x_{\text {rel }}(\text { trait } j)\right] / a(\text { trait } i) \\
& =\left(x_{g j}-x_{\text {relj } j}\right) / a_{i}
\end{aligned}
$$


and

$r_{G}=\left[\left(b_{j i} b_{i j}\right) /\left(b_{i j} b_{j j}\right)\right]^{1 / 2}$.

The actual method used in this paper is a modification of Falconer's proband method suggested by Reich et al., (1972), which takes into account the differences in variance between the general population of probands, and the population of relatives. This computes the correlation of liability amongst relatives, but, as the variance in each population is the same, this is effectively the same as the regression calculated above. The method may therefore be adjusted, as before, in order to compute genetic correlations. The regression coefficients are:

$$
b j i=\frac{x_{g j}-x_{\mathrm{rel} j}\left[1-\left(x_{g j}^{2}-x_{\mathrm{relj} j}^{2}\right)\left(1-x_{g i} / a_{i}\right)\right]^{1 / 2}}{a_{i}+x_{\mathrm{relj}}^{2}\left(a_{i}-x_{g i}\right)} .
$$

For comparison, analyses were also performed using the analysis of variance method on arcsine transformed data (Cochran, 1940), and also the unmodified proband method. The results of these were not different from those obtained using an analysis of variance on untransformed data, and the modified proband method, respectively, and therefore these methods were not considered further. It is probable that this uniformity is attributable to the very small changes in variance associated with the defect traits.

\section{Simulation}

(i) Method

To compare the methods of analysis a multivariate normally distributed data set with no environmental correlation between full sibs was simulated. The population generated contained three defect traits and had a family structure similar to that in the broiler data available, with 150 sires each having 6 dams with 24 progeny per dam $(N=21,600)$. Traits were assigned a fixed value of heritability on the continuous scale $\left(h_{1}^{2}=0.40, h_{2}^{2}=0.25\right.$, $h_{3}^{2}=0 \cdot 10$ ), and a genetic correlation which was the same between all three traits, this being either $0 \cdot 50,0.25$ or $0 \cdot 10$. The population was then truncated at various different incidences $(p=0.05,0.02,0.005)$, which were assigned to each of the values of heritability in turn, and repeated for the three different genetic correlations. Each truncated population was subjected to analysis of variance and the modified proband method using full-sib families. Estimates of heritability calculated on the $0-1$ data by analysis of variance were corrected for continuity by $p(1-p) / z^{2}$, where $p$ and $z$ were the sample values. Means of 18-25 replications were taken for each combination of parameters, which enabled the calculation of empirical standard errors.

\section{(ii) Results and discussion}

The results (table l) show that for a known distribution, without environmental complications, an analysis of variance produces consistently higher estimates of heritability than does the proband method at the low incidences considered here. The estimates for the proband method are usually less biased than those from the analysis of variance, except when the incidence 
TABLE 1

A comparison of mean estimates of heritability and genetic correlation obtained using (1) AOV and (2) Modified proband methods on truncated data from 18-25 repetitions of simulation. Incidence $T l=0.05, T 2=0.02, T 3=0.005$ of trait $i$

\begin{tabular}{|c|c|c|c|c|c|c|}
\hline \multicolumn{7}{|c|}{ Heritability $\pm S E$ (AOV transformed to continuous scale) } \\
\hline & & & T1 & $\mathrm{T} 2$ & T3 & \\
\hline & $h^{2}=0.40$ & & $\begin{array}{l}1 . \\
2 .\end{array}$ & $\begin{array}{l}0.50 \pm 0.014 \\
0.38 \pm 0.008\end{array}$ & $\begin{array}{l}0.55 \pm 0.018 \\
0.37 \pm 0.009\end{array}$ & $\begin{array}{l}0.59 \pm 0.048 \\
0.33 \pm 0.018\end{array}$ \\
\hline & $h^{2}=0.25$ & & $\begin{array}{l}1 . \\
2 .\end{array}$ & $\begin{array}{l}0.28 \pm 0.007 \\
0.24 \pm 0.006\end{array}$ & $\begin{array}{l}0.30 \pm 0.014 \\
0.23 \pm 0.008\end{array}$ & $\begin{array}{l}0.35 \pm 0.034 \\
0.23 \pm 0.017\end{array}$ \\
\hline & $h^{2}=0.10$ & & $\begin{array}{l}1 . \\
2 .\end{array}$ & $\begin{array}{l}0.11 \pm 0.006 \\
0.10 \pm 0.005\end{array}$ & $\begin{array}{l}0.11 \pm 0.010 \\
0.10 \pm 0.008\end{array}$ & $\begin{array}{l}0.10 \pm 0.016 \\
0.05 \pm 0.019\end{array}$ \\
\hline $\mathrm{h}_{1}^{2}$ & $\mathrm{~h}_{2}^{2}$ & $h_{3}^{2}$ & & $\begin{array}{l}\text { ic Correlations } \\
\qquad \mathbf{T}_{1}, \mathbf{T}_{2}\end{array}$ & $T_{1}, T_{3}$ & $T_{2}, T_{3}$ \\
\hline 0.40 & $0 \cdot 25$ & $0 \cdot 10$ & $\begin{array}{l}1 . \\
2 .\end{array}$ & $\begin{array}{c}r_{G}=0.50 \\
0.48 \pm 0.027 \\
0.53 \pm 0.025\end{array}$ & $\begin{array}{l}0.54 \pm 0.075 \\
0.63 \pm 0.086\end{array}$ & $\begin{array}{l}0.67 \pm 0.110 \\
0.73 \pm 0.106\end{array}$ \\
\hline $0 \cdot 25$ & $0 \cdot 10$ & 0.40 & $\begin{array}{l}1 . \\
2 .\end{array}$ & $\begin{array}{l}0.49 \pm 0.046 \\
0.52 \pm 0.047\end{array}$ & $\begin{array}{l}0.47 \pm 0.029 \\
0.56 \pm 0.030\end{array}$ & $\begin{array}{l}0.44 \pm 0.059 \\
0.52 \pm 0.064\end{array}$ \\
\hline $0 \cdot 10$ & 0.40 & 0.25 & $\begin{array}{l}1 . \\
2 .\end{array}$ & $\begin{array}{l}0.41 \pm 0.025 \\
0.48 \pm 0.027\end{array}$ & $\begin{array}{l}0.48 \pm 0.066 \\
0.53 \pm 0.069\end{array}$ & $\begin{array}{l}0.53 \pm 0.060 \\
0.59 \pm 0.058\end{array}$ \\
\hline 0.40 & $0 \cdot 25$ & $0 \cdot 10$ & 1. & $\begin{array}{c}r_{G}=0.25 \\
0.22 \pm 0.022 \\
0.25 \pm 0.026\end{array}$ & $\begin{array}{l}0.27 \pm 0.063 \\
0.34 \pm 0.071\end{array}$ & $\begin{array}{l}0.37 \pm 0.077 \\
0.41 \pm 0.096\end{array}$ \\
\hline 0.25 & $0 \cdot 10$ & 0.40 & $\begin{array}{l}1 . \\
2 .\end{array}$ & $\begin{array}{l}0.21 \pm 0.036 \\
0.23 \pm 0.038\end{array}$ & $\begin{array}{l}0.25 \pm 0.028 \\
0.31 \pm 0.032\end{array}$ & $\begin{array}{l}0.23 \pm 0.048 \\
0.27 \pm 0.032\end{array}$ \\
\hline $0 \cdot 10$ & 0.40 & $0 \cdot 25$ & $\begin{array}{l}1 . \\
2 .\end{array}$ & $\begin{array}{l}0.21 \pm 0.020 \\
0.25 \pm 0.023\end{array}$ & $\begin{array}{l}0.29 \pm 0.065 \\
0.33 \pm 0.068\end{array}$ & $\begin{array}{l}0.28 \pm 0.075 \\
0.33 \pm 0.080\end{array}$ \\
\hline 0.40 & $0 \cdot 25$ & $0 \cdot 10$ & $\begin{array}{l}1 . \\
2 .\end{array}$ & $\begin{array}{c}r_{G}=0.10 \\
0.08 \pm 0.025 \\
0.11 \pm 0.023\end{array}$ & $\begin{array}{l}0.15 \pm 0.067 \\
0.18 \pm 0.079\end{array}$ & $\begin{array}{l}0.12 \pm 0.103 \\
0.14 \pm 0.117\end{array}$ \\
\hline 0.25 & $0 \cdot 10$ & 0.40 & $\begin{array}{l}1 . \\
2 .\end{array}$ & $\begin{array}{l}0.05 \pm 0.020 \\
0.06 \pm 0.023\end{array}$ & $\begin{array}{l}0.10 \pm 0.026 \\
0.13 \pm 0.034\end{array}$ & $\begin{array}{l}0.10 \pm 0.042 \\
0.10 \pm 0.058\end{array}$ \\
\hline $0 \cdot 10$ & 0.40 & $0 \cdot 25$ & $\begin{array}{l}1 . \\
2 .\end{array}$ & $\begin{array}{l}0.09 \pm 0.023 \\
0.10 \pm 0.026\end{array}$ & $\begin{array}{l}0.12 \pm 0.038 \\
0.14 \pm 0.046\end{array}$ & $\begin{array}{l}0.10 \pm 0.054 \\
0.10 \pm 0.067\end{array}$ \\
\hline
\end{tabular}

is very low. The level of heritability does not seem to have an important effect on the bias of the estimates. The sampling variances of both kinds of estimates increase as the incidence falls, and are generally higher for the analysis of variance than proband method.

Conversely, genetic correlations obtained by the proband method on the underlying scale are consistently higher than those on the $0-1$ scale from the analysis of variance. There does not appear to be much difference between the two methods in bias of the estimates, the level of agreement between methods and with the actual value generally being quite good. As for the heritabilities, the estimates are not so consistent as the incidence becomes smaller and also as the true genetic correlation decreases. This can be seen by the relative magnitude of the standard errors relative to the 
size of the estimates. These findings support the conclusions of Olausson and Ronningen (1975), who found that the estimates made on $0-1$ data are acceptable, given that the bias is decreasing as the heritability increases. The sampling variances of the genetic correlation estimates from the analysis of variance are generally smaller than those from the proband method.

The conclusions from the simulation seem to be that, where possible, heritability estimates should be taken from the proband analysis, while the genetic correlations can be taken from either method. In practice continuous traits such as live-weight may also be included in the data. Olausson and Ronningen (1975) showed by simulation that genetic correlations between a continuous trait and a $0-1$ trait will be almost the same as if both traits were estimated on an underlying distribution, except at low heritability and low incidence. This, together with the fact that mixed-model packages are more flexible in their ability to correct for other factors, points to the use of analysis of variance techniques for the estimation of genetic correlations.

\section{Analysis of pedigree data}

\section{(i) Materials and methods}

Data consisted of records from three pedigree broiler strains collected over an 18-month period. All birds were assessed by the same selection team on various growth and conformational traits at 6 weeks old. Five basic traits were considered in the present study. These were:

(a) live-weight (LWT)

(b) crooked-toe (CT), in which curling of the toes give the bird's feet a "crab-like" appearance

(c) bow (B), in which bowing of the tarsometatarsi and, to a lesser extent, the tibiotarsi occurs

(d) splay (S), the opposite of bow, leading to a valgus deformity of the tarsometatarsi

(e) knobby-keel (KK) in which the anterior tip of the breast bone is prominent.

Two composite traits were also included in the analyses, leg problems (LP) and keel problems (KP). These included the leg and keel defects mentioned above, together with other traits which have not been presented here, namely twisted leg, tibial dyschondroplasia and twisted keel. Twisted leg and twisted keel were seen to be rather rare $(p<0.005)$, and therefore reasonable estimates of genetic parameters for these traits were not obtainable. Tibial dyschondroplasia as scored by visual assessment in the field is not thought to reflect the incidence of cartilage abnormality associated with true dyschondroplasia (Mercer, 1983).

Data were subjected to both full-sib and paternal half-sib analyses using both analysis of variance and a modified proband technique. Data from males and females were combined as results, not presented here, indicate that estimates obtained for sexes analysed separately are similar to those from analyses of pooled data. At any one time nine mating groups of each selected line were contributing replacements. Eggs from all groups were set together and the resulting offspring placed on one farm. 
In the analyses of variance a correction for hatch week was included in the model thereby removing possible variation attributable to common environment and also adjusting for the time of year at which the hatch was taken. The model used was therefore as follows:

$$
Y_{i j k l m}=\mu+a_{i}+b_{j(i)}+c_{k}+d_{l}+e_{i j k l m}
$$

where

$$
\begin{aligned}
Y_{i j k l m} & =\text { independent variable } \\
\mu & =\text { mean } \\
a_{i} & =i \text { th sire (random) } \\
b_{j(i)} & =j \text { th dam nested within } i \text { th sire (random) } \\
c_{k} & =k \text { th hatch week (fixed) } \\
d_{l} & =l \text { th sex (fixed) } \\
e_{i j k l m} & =\text { error term. }
\end{aligned}
$$

The coefficients of sire and dam components of variance computed for the expected mean squares are presented in table 2 .

In the modified proband method, effects of hatch week were removed by ignoring, for each affected individual, all records from the contemporaneous hatch week. Similarly, when half-sib analyses were performed, both hatch contemporaries and all records of full-sibs of a given individual were ignored.

Standard errors of the above analyses have not been shown. Results not presented, however, indicate that the standard errors of estimates made on actual full-sib data are in good agreement with the standard deviations among replicates of the simulation. The standard errors presented for the mean of 18-25 simulated replicates in table 1 are thus about one-fifth of the standard errors of the estimates from the data. Standard errors of half-sib estimates appear to be similar in size to those of full-sib estimates.

\section{(ii) Results and discussion}

Means for the traits analysed are presented in table 3 . The phenotypic variance of each of the defect traits is merely a binomial function of its incidence $p(1-p)$. As can be seen, the incidence of each of the individual defect traits is low, ranging from 1-5 per cent, whereas that of the pooled leg problems is rather higher. It is worth noting that these incidences apply to a pedigree flock being carefully recorded, and that not all affected birds would be downgraded in a commercial flock or at the processing plant.

Phenotypic correlations between the defect traits were typically very low, not more than $\pm 0 \cdot 04$. These have not been presented because they may have been influenced by underscoring, birds with more than one defect actually only being scored on one, and because some traits, such as bow and splay, are mutually exclusive. Phenotypic correlations between live weight and defect traits were also very small, no more than \pm 0.06 , and were positive for crooked toe and bow, typically slightly negative for splay.

Estimates of genetic parameters from both analysis of variance and proband methods are given in subsequent tables for the purposes of illustrating the conclusions of the simulation, and also to compare the level of agreement between the two methods. Table 4 presents estimates of 


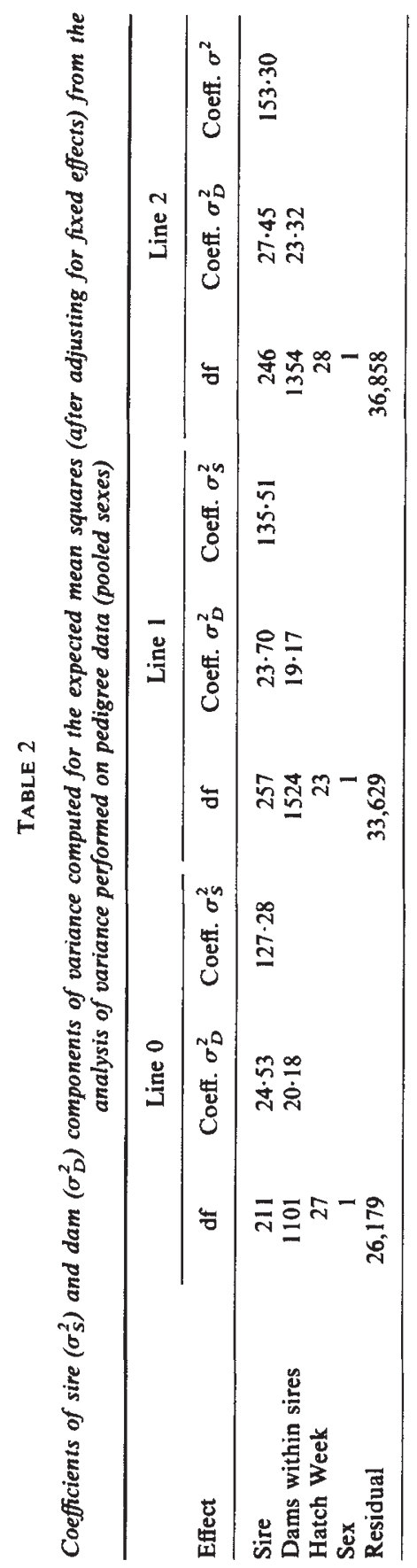


TABLE 3

Means of traits ${ }^{+}$examined ( = per cent incidence in defect traits) plus number of records on males (M) and females $(F)$

\begin{tabular}{|c|c|c|c|c|c|c|c|c|c|}
\hline & & LWT $(g) \pm S D$ & CT & B & $S$ & KK & LP & KP & No. \\
\hline \multirow[t]{3}{*}{ Line 0} & $\mathbf{M}$ & $1574 \pm 193$ & $5 \cdot 6$ & $2 \cdot 6$ & $3 \cdot 4$ & $3 \cdot 0$ & $11 \cdot 5$ & $3 \cdot 7$ & 13,171 \\
\hline & $\mathrm{F}$ & $1313 \pm 136$ & $4 \cdot 3$ & 1.9 & 1.4 & 0.3 & $7 \cdot 4$ & 0.3 & 14,349 \\
\hline & $M+F$ & 1438 & $4 \cdot 9$ & $2 \cdot 2$ & $2 \cdot 3$ & $1 \cdot 6$ & $9 \cdot 4$ & $2 \cdot 0$ & 27,520 \\
\hline \multirow[t]{3}{*}{ Line 1} & $\mathbf{M}$ & $1718 \pm 210$ & $4 \cdot 3$ & $2 \cdot 0$ & $5 \cdot 5$ & 3.5 & $11 \cdot 7$ & $4 \cdot 3$ & 16,930 \\
\hline & $\mathrm{F}$ & $1424 \pm 153$ & $2 \cdot 6$ & 0.9 & $2 \cdot 2$ & $0 \cdot 1$ & $5 \cdot 7$ & $0 \cdot 2$ & 18,506 \\
\hline & $M+F$ & 1564 & $3 \cdot 4$ & $1 \cdot 5$ & $3 \cdot 8$ & $1 \cdot 7$ & $8 \cdot 6$ & $2 \cdot 2$ & 35,436 \\
\hline \multirow[t]{3}{*}{ Line 2} & $\mathbf{M}$ & $1637 \pm 191$ & $6 \cdot 2$ & $1 \cdot 4$ & $4 \cdot 1$ & 5.0 & $11 \cdot 6$ & $6 \cdot 1$ & 18,513 \\
\hline & $F$ & $1353 \pm 132$ & $3 \cdot 6$ & $1 \cdot 3$ & 1.9 & 0.3 & 6.8 & 0.4 & 19,975 \\
\hline & $M+F$ & 1490 & $4 \cdot 8$ & $1 \cdot 3$ & $3 \cdot 0$ & $2 \cdot 5$ & $9 \cdot 1$ & $3 \cdot 1$ & 38,488 \\
\hline
\end{tabular}

$\dagger \mathrm{LWT}=$ Live weight, $\mathrm{CT}=$ crooked toes, $\mathrm{B}=$ bow, $\mathrm{S}=$ splay, $\mathrm{KK}=\mathrm{knobbly}-\mathrm{keel}, \mathrm{LP}=$ total leg problems, $\mathrm{KP}=$ total keel problems.

heritabilities and genetic correlations for discrete traits. As expected, the proband method gave generally lower estimates of heritabilities and higher estimates of genetic correlations than did the analyses of variance.

Two aspects of importance to the breeder are immediately obvious. The first of these is that each of the defect traits has a relatively high component of heritable variation, of the order of $20-30$ per cent, that of knobby keel being slightly less than those of the leg defects. In instances where the incidence of males is greater than that of females (as in knobby keel), the heritability estimate for sexes pooled will be slightly less than that calculated using male records only. Secondly, the leg defects all have positive (i.e., unfavourable) genetic correlations with live-weight. Knobby keel seems to have a variable relationship with live-weight, this being positive in line 2 . Leg problems appear to be positively correlated with each other, with the possible exception of bow and splay. Splay seems to have a positive genetic correlation with knobby keel, but the relationship between the latter and the other leg defects is uncertain. The genetic correlations between defect traits and live weight are much larger than the phenotypic, due partly to the nature of the $0-1$ scoring, but also presumably because there was a negative environmental correlation between the traits-birds with leg problems were less vigorous.

Results of an analysis of pooled defects are presented in table 5. These support the findings of table 4 . Leg and keel defects grouped as a whole also appear to have a moderate heritability; but they are not more heritable than the individual traits because they are not completely correlated. Leg problems have a consistent, positive genetic correlation of about 20 per cent with live-weight, while the relationship between keel problems and the other traits remains variable.

The above results obviously imply that the incidence of skeletal defects may be reduced by selection against them, in agreement with estimates previously obtained for tibial dyschondroplasia (Sheridan et al., 1978) and twisted leg (Hartmann, 1979). Problems remain, however, in the fact that leg defects and live-weight are positively correlated, so selection programmes for body weight are likely to increase or at best maintain current levels of 
TABLE 4

A comparison of the estimates of $h^{2}$ per cent (diagonal) and $r_{G}$ per cent obtained using (1) Modified proband and (2) AOV ( $h^{2}$ corrected for continuity) methods. Full-sib lower triangle, Paternal half-sib upper triangle (males and females pooled)

\begin{tabular}{|c|c|c|c|c|c|c|c|c|}
\hline Line 0 & & & & LWT & CT & B & $\mathbf{S}$ & KK \\
\hline \multirow[t]{2}{*}{ LWT } & 1. & - & & - & - & - & - & - \\
\hline & 2. & 28 & & 26 & 9 & 28 & 25 & -16 \\
\hline \multirow[t]{2}{*}{ CT } & 1. & - & 30 & & 29 & -31 & -17 & -32 \\
\hline & 2. & 7 & 50 & & 42 & 7 & 29 & 11 \\
\hline \multirow[t]{2}{*}{ B } & 1. & - & 1 & 18 & & 13 & -29 & -83 \\
\hline & 2. & 21 & 16 & 29 & & 28 & -21 & -10 \\
\hline \multirow[t]{2}{*}{$\mathbf{S}$} & 1. & - & 17 & $x$ & 20 & & 14 & $x$ \\
\hline & 2. & 11 & 7 & -11 & 62 & & 16 & \\
\hline \multirow[t]{3}{*}{ KK } & 1. & - & -21 & -3 & 6 & 17 & & 8 \\
\hline & 2. & 3 & -8 & -3 & 7 & 27 & & 24 \\
\hline & & LWT & CT & B & $\mathbf{S}$ & KK & & \\
\hline \multicolumn{4}{|l|}{ Line 1} & LWT & CT & B & $\mathbf{S}$ & $\mathbf{K}$ \\
\hline \multirow[t]{2}{*}{ LWT } & 1. & - & & - & - & - & - & - \\
\hline & 2. & 30 & & 25 & 32 & 34 & 12 & 1 \\
\hline \multirow[t]{2}{*}{ CT } & 1. & - & 28 & & 29 & 40 & 39 & -2 \\
\hline & 2. & 18 & 35 & & 29 & 60 & 28 & -12 \\
\hline \multirow[t]{2}{*}{ B } & 1. & - & 35 & 24 & & 15 & 27 & -19 \\
\hline & 2. & 25 & 39 & 51 & & 18 & -7 & -30 \\
\hline \multirow[t]{2}{*}{$\mathbf{S}$} & 1. & - & 33 & 8 & 22 & & 20 & 38 \\
\hline & 2. & 7 & 29 & 3 & 32 & & 18 & 25 \\
\hline \multirow[t]{3}{*}{ KK } & 1. & - & -32 & 4 & 4 & 26 & & 16 \\
\hline & 2. & -5 & -18 & -5 & 4 & 24 & & 20 \\
\hline & & LWT & CT & B & $\mathbf{S}$ & KK & & \\
\hline \multicolumn{4}{|l|}{ Line 2} & LWT & $\mathrm{CT}$ & B & $\mathbf{S}$ & KK \\
\hline \multirow[t]{2}{*}{ LWT } & 1. & - & & - & - & - & - & - \\
\hline & 2. & 24 & & 18 & 45 & 30 & 2 & 12 \\
\hline \multirow[t]{2}{*}{$\mathrm{CT}$} & 1. & - & 23 & & 14 & 55 & 26 & 30 \\
\hline & 2. & 23 & 38 & & 23 & 46 & 36 & $x$ \\
\hline \multirow[t]{2}{*}{ B } & 1. & - & 50 & 18 & & 5 & 42 & $x$ \\
\hline & 2. & 17 & 36 & 27 & & 12 & -8 & 10 \\
\hline \multirow[t]{2}{*}{$\mathbf{S}$} & 1. & - & 22 & 15 & 26 & & 29 & $x$ \\
\hline & 2. & 0 & 16 & -9 & 55 & & 30 & 5 \\
\hline \multirow[t]{3}{*}{ KK } & 1. & - & $x$ & $x$ & $x$ & 7 & & 5 \\
\hline & 2. & 19 & 11 & -9 & 14 & 10 & & 20 \\
\hline & & LWT & CT & B & $\mathbf{S}$ & KK & & \\
\hline
\end{tabular}

$-=$ not calculated.

$\bar{x}=$ estimate unobtainable as regressions of $b_{i j}$ and $b_{j i}$ are of opposite signs, implying that correlation is small.

abnormalities. This issue will be considered further elsewhere (Mercer and Hill, in preparation).

More generally, it is likely that intense selection pressure over many generations on a desirable metric trait has had an adverse effect on fitness, assuming birds with leg abnormalities are indeed less fit; and that fitness levels have only been maintained by breeders by concurrent selection to reduce the incidence of defects. Fortunately, the positive correlations among 
TABLE 5

Obtained using (1) Modified proband and (2) AOV (h corrected for continuity) methods on pooled defects. Full-sib lower triangle. Paternal Half-sib upper triangle (males and females pooled)

\begin{tabular}{|c|c|c|c|c|c|c|}
\hline Line 0 & & & & LWT & LP & KP \\
\hline \multirow[t]{2}{*}{ LWT } & 1. & - & & - & - & - \\
\hline & 2. & 28 & & 26 & 24 & -14 \\
\hline \multirow[t]{2}{*}{ LP } & 1. & - & 18 & & 9 & -116 \\
\hline & 2. & 18 & 30 & & 22 & 5 \\
\hline \multirow[t]{3}{*}{$\mathbf{K P}$} & 1. & - & -12 & 18 & & 6 \\
\hline & 2. & 4 & -2 & 24 & & 17 \\
\hline & & LWT & LP & KP & & \\
\hline \multicolumn{2}{|l|}{ Line I } & & & LWT & LP & KP \\
\hline \multirow[t]{2}{*}{ LWT } & 1. & - & & - & - & - \\
\hline & 2. & 29 & & 25 & 33 & -3 \\
\hline \multirow[t]{2}{*}{ LP } & 1. & - & 22 & & 21 & 17 \\
\hline & 2. & 21 & 28 & & 19 & 10 \\
\hline \multirow[t]{3}{*}{ KP } & 1. & - & -16 & 21 & & 11 \\
\hline & 2. & -5 & -7 & 22 & & 13 \\
\hline & & LWT & $\mathbf{L P}$ & $\mathbf{K P}$ & & \\
\hline \multicolumn{2}{|l|}{ Line 2} & & & LWT & LP & KP \\
\hline \multirow[t]{2}{*}{ LWT } & 1. & - & & - & - & - \\
\hline & 2. & 24 & & 18 & 33 & 14 \\
\hline \multirow[t]{2}{*}{ LP } & 1. & - & 20 & & 15 & $x$ \\
\hline & 2. & 19 & 30 & & 20 & 12 \\
\hline \multirow[t]{3}{*}{$\mathbf{K P}$} & 1. & - & $x$ & 6 & & 9 \\
\hline & 2. & 21 & 14 & 9 & & 18 \\
\hline & & LWT & LP & $\mathbf{K P}$ & & \\
\hline
\end{tabular}

$-=$ not calculated, $x=$ estimate unobtainable (see table 4 ).

the defects enable them to be considered as a whole, obviating the need for detailed recording of separate abnormalities, and enabling greater selection pressure to be applied.

Acknowledgements. We are grateful to Ross Breeders Ltd., who supplied the data, and to the Ministry of Agriculture, Fisheries and Food for a studentship to J.T.M.

\section{REFERENCES}

COCHRAN, W. G. 1940. The analysis of variance when experimental errors follow the Poisson or Binomial Laws. Annals of Mathematical Statistics, $11,335-347$.

CRAIG, F. R. 1978. Leg problems and their economic implications. Proceedings of the National Meeting on Poultry Health and Condemnations, 13, 18-23.

ELSTON, R. G. 1977. Response to query on estimating "heritability" of a dichotomous trait. Biometrics, 33, 232-233.

FALCONER, D. S. 1965. The inheritance of liability to certain diseases, estimated from the incidence amongst relatives. Annals of Human Genetics, 29, 51-76.

FALCONER, D. S. 1967. The inheritance of liability to diseases with variable age of onset, with particular reference to diabetes mellitus. Annals of Human Genetics, 31, 1-20.

HARTMANN, W. (1979). Line and family effects on the incidence of "twisted legs" in meat chickens. Proceedings of the British Poultry Breeders Roundtable, Glasgow. 
HARVEY, W. R. 1977. User's guide for LSML76. Ohio State University.

HILL, W. G. AND SMITH, C. 1977. Alternative response to query on estimating "heritability" of a dichotomous trait. Biometrics, 33, 234-236.

LUSH, J. L. LAMOREUX, W. F. AND HAZEL, L. N. 1948. The heritability of resistance to death in the fowl. Poultry Science, 27, 375-388.

MERCER, J. T. 1983. The genetics of leg abnormalities in poultry, with particular reference to dyschondroplasia. Ph.D. Thesis, University of Edinburgh.

OLAUSSON, A. AND RONNINGEN, R. 1975. Estimation of genetic parameters for threshold characters. Acta Agriculturae Scandinavica, 25, 200-208.

REICH, T., JAMES, J. W. AND MORRIS, C. A. 1972. The use of multiple thresholds in determining the mode of transmission of semi-continuous traits. Annals of Human Genetics, $36,163-184$.

ROBERTSON, A. AND LERNER, I. M. 1949. The heritability of all-or-none traits: viability of poultry. Genetics, 34, 395-411.

SHERIDAN, A. K., HOWLETT, C. R. AND BURTON, R. W. 1978. The inheritance of tibial dyschondroplasia in broilers. British Poultry Science, 19, 491-499. 